\title{
Neuropsychological Parameters as Potential Biomarkers for Alzheimer's Disease
}

\author{
Jinglong $\mathbf{W u} \cdot$ Yinghua $\mathbf{Y u} \cdot$ Jiajia Yang
}

Published online: 18 April 2012

(C) Springer Science+Business Media, LLC 2012

\begin{abstract}
Alzheimer's disease (AD) is a progressive neurodegenerative disease. It is of great importance that we find efficient preclinical markers that can be used in clinics. The neuropathological features associated with $\mathrm{AD}$ brain include the progressive formation of insoluble amyloid plaques and vascular deposits consisting of the amyloid $\beta$ peptide in the brain and neuron loss that innervates regions such as the hippocampus and the cortex. These lesions are considered to cause the abnormal sensory information processing and brain dysfunction of $\mathrm{AD}$ patients. Combined cognitive and sensory as well as neuroimaging approaches have advantages to find the altered cognitive symptoms and brain dysfunction in the early stage in $\mathrm{AD}$ involved mild memory or planning problems. This review provides an overview of the neuropsychological impairments in patients with $\mathrm{AD}$, which may be used as potential biomarkers for early diagnosis of $\mathrm{AD}$.
\end{abstract}

Keywords Alzheimer's disease · Mild cognitive impairment $\cdot$ Cognition $\cdot$ Neuroimaging .

Electroencephalogram $\cdot$ Preclinical markers $\cdot$ Biomarkers

\section{Introduction}

Dementia is a brain disorder that mostly occurs in later life and represents a growing public health concern. Alzheimer's disease (AD) is the most common form of dementia, accounting for $50 \%$ to $80 \%$ of dementia cases. AD is a pathophysiologically

\footnotetext{
J. Wu $(\bowtie) \cdot \mathrm{Y}$. Yu $\cdot$ J. Yang

Biomedical Engineering Laboratory, Graduate School of Natural

Science and Technology, Okayama University,

3-1-1 Tsushima-Naka, Kita-Ku,

Okayama 700-8530, Japan

e-mail:wu@mech.okayama-u.ac.jp
}

complex, slowly progressive, and irreversible neurodegenerative disease of the brain. To date, the only treatments of $\mathrm{AD}$ are symptomatic. Furthermore, AD cannot be diagnosed until the advanced stages of the disease, when the evidence of cognitive or memory deficits caused by $\mathrm{AD}$ has been clinically established by neuropsychological, cognitive tests. Amnestic mild cognitive impairment (aMCI) is a relatively recent term used to describe people who have some problems with their memory but do not actually have dementia [1-3]. However, aMCI is considered to be a transitional stage between aging and $\mathrm{AD}$, and recently studies $[4,5]$ have indicated that about $12 \%$ annually progress from aMCI to $\mathrm{AD}$. Trials of large-scale detection markers are currently being conducted in the worldwide $\mathrm{AD}$ research networks. To effectively prevent and treat in preclinical stages, the reliable early detection of mild cognitive impairment (MCI) and $\mathrm{AD}$ is of great importance.

The ideal biomarkers for $\mathrm{AD}$ are measured against the criteria established by expert consensus statements [6]. They should reflect neuropathological characteristics and be validated in neuropathologically confirmed patients. Their sensitivity to detect $\mathrm{AD}$ should be at least $80 \%$ and their ability to differentiate $\mathrm{AD}$ patients from other dementias should also be at least $80 \%$. In recent years, large numbers of promising results have indicated that many molecular level biomarkers can reliably predict $\mathrm{AD}$. For example, measuring tau (t-tau), $\beta$-amyloid peptide $(\mathrm{A} \beta 42)$, or hyperphosphorylated tau (p-tau) developed in the cerebrospinal fluid (CSF) can reliably diagnose $\mathrm{AD}$ with accuracy in the range of between $80 \%$ and $90 \%$ [7-9]. Furthermore, the combined measurements of total t-tau, $A \beta 42$, and hyperphosphorylated p-tau levels in the CSF and regional flow or mediotemporal lobe atrophy may demonstrate better predictive ability than diagnostic approaches alone in MCI studies [10-12]. More recent biomarker research [13-17] reported that the increased $\beta$-site amyloid precursor protein (APP) 
cleaving enzyme 1 (BACE1) protein levels in the CSF were associated with increased risk ratios for patients with $\mathrm{MCI}$ compared with normal aging and AD. Thus, the diagnostic value of BACE1 activity may be useful in clinical trials on, for example, BACE1 inhibitors. Although these biomarkers can reliably diagnose $\mathrm{AD}$ or $\mathrm{MCI}$, the one major challenge is that taking samples of the CSF is an invasive procedure, thus limiting their usability in early diagnostics. Therefore, it is difficult to achieve the establishment of a clinical routine.

With the new diagnostic criteria that were advocated at the Alzheimer's Association International Conference 2011 in Paris [18, 19], neuroimaging techniques that have been used to investigate changes of brain structure and function have become core markers of $\mathrm{AD}$ in asymptomatic and prodromal stages. Functional magnetic resonance imaging (fMRI) and positron emission tomography (PET) are effective methods and are widely used to explore the underlying neural mechanisms of perceptual processing. From the late 20th century, some researchers have used these functional imaging techniques to investigate the brain function in $\mathrm{MCI}$ and $\mathrm{AD}$ patients. Compared to PET, fMRI has some advantages for examining $\mathrm{MCI}$ and $\mathrm{AD}$ patients because it is noninvasive, does not require the injection of contrast agent, and there is an absence of exposure to ionizing radiation. Moreover, fMRI has superior spatial resolution and the ability to obtain both anatomic and functional images in the same session. Therefore, fMRI is likely to be particularly useful for detecting the brain dysfunction of patients with early stage $\mathrm{AD}$ compared to natural aging and MCI. Furthermore, the electroencephalogram (EEG) is also a useful objective tool (referring to the measuring of the physiology and pathophysiology of human brain function) [20]. EEG can detect brain activity within milliseconds (excellent considering its extremely high temporal resolution), and can also allow noninvasive measurements of brain dysfunction [21]. Based on these characteristics, the combination of fMRI and EEG is considered to be an extremely useful technique for evaluating the spatiotemporal functional changes in human brain, maybe also provide a powerful tool for diagnosis $\mathrm{MCI}$ and $\mathrm{AD}$.

In this article, we first review the general preclinical impairments of $\mathrm{AD}$ and $\mathrm{MCI}$ across a variety of cognitive domains including episodic memory, executive functioning, attention, visuospatial skill, and perceptual modality. Then, we focus on neuroimaging studies including fMRI, as well as EEG techniques on $\mathrm{AD}, \mathrm{MCI}$ and normal aging. We wish to provide some novel evidence for the early clinically diagnostic criteria of $\mathrm{AD}$ and $\mathrm{MCI}$.

\section{Cognitive Deficits in MCI and AD}

In the latter part of the 19th century, a definition of $\mathrm{AD}$ was published $[22,23]$. The definition notes that a diagnosis of probable $\mathrm{AD}$ should include impairments in two or more areas of cognition, with progressive worsening of memory and other cognitive functions. Then, two clinical standardized systems were established including the clinical dementia rating (CDR) [24] and the global deterioration scale for aging and dementia (GDS) [25]. These can reliably assess the boundaries of aging and dementia on patients' cognitive and functional performance in the areas of memory, orientation, judgment and problem solving, community affairs, home and hobbies, and personal care. These two systems remain today as benchmarks for clinicians. For the current discussion, as shown in Fig. 1, a CDR of 0 and GDS of 1 can be considered as normal, a CDR of 0.5 or GDS of 2 to 3 can refer to an individual with a MCI, and a CDR of more than 1 and GDS more than 4 can refer to AD [2]. However, Gauthier et al. [1] also emphasized that these stages may describe individuals with very mild dementia, and are not diagnostic instruments.

Another widely used tool for assessing cognitive impairment was the mini-mental state examination (MMSE) that was introduced by Marshall Folstein and others in 1975 [26]. The MMSE is a brief 30-point questionnaire that can effectively assess the global cognitive mental status, and includes tests for arithmetic, memory, and orientation. Clinicians state that those with MCI tend to score in the 26- to 30-point range [27], and those with $\mathrm{AD}$ tend to score less than 26 , with a score of 21 to 26 points referring to mild $A D$, 10 to 20 points referring to moderate $\mathrm{AD}, 10$ to 14 points referring to moderately severe $\mathrm{AD}$, and less than 10 points referring to severe AD. However, even though the MMSE has been the most commonly used test for complaints of memory problems or when a diagnosis of dementia is being considered, the sensitivity of the MMSE has been rated at about $80 \%[28,29]$ and may not represent the cognitive function deficits of all individuals. Therefore, the MMSE can be used to indicate the presence of a cognitive impairment but is not suitable for making a diagnosis of $\mathrm{AD}$.

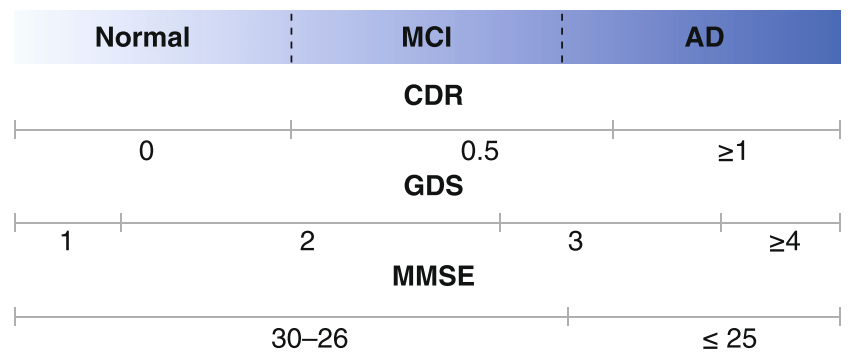

Fig. 1 The overlap among clinical diagnostic criteria for mild cognitive impairment (MCI) and Alzheimer's disease (AD), and corresponding ratings on clinical dementia rating (CDR), global deterioration scale (GDS), and mini-mental state examination (MMSE). While these tests can be used to observe the cognitive impairment of $\mathrm{AD}$ and MCI patients, they are not suitable for making a clinical diagnosis of $\mathrm{AD}$ and $\mathrm{MCI}$ 
Recently, a large number of studies [30, 31] have used cognitive tasks to attempt to find the preclinical cognitive markers of AD. For instance, Bäckman et al. [32] used freerecall tasks (eg, recall of presented words) to investigate the episodic memory of normal older individuals and $\mathrm{AD}$ patients. This study convincingly demonstrates that the episodic memory deficits of AD clearly occur, and it is possible to detect during a preclinical period spanning several years. Moreover, previous studies also demonstrate that $\mathrm{AD}$ patients are impaired when they have to recall the colors of previously studied figures $[30,33]$, or when they have to discriminate pairs of faces with names [34], or parts of objects [35]. Furthermore, the somatosensory system is a diverse sensory system comprising the receptors and processing centers to produce the sensory modalities. Tactile spatial discrimination is one of the major manual learning and memory skills of humans. To differentiate two different objects by touch alone, humans need to store the spatial information of the first object in their working memory and then compare the spatial construction of the first object to that of the second. This procedure activates a widely distributed cerebral network that mainly includes areas involved with the initial processing of skin indentations, the high-class areas for computation and elaborate reconstruction of shapes and the prefrontal cortex, which is activated for tactile working memory processing [36]. The abnormal sensory information process of $\mathrm{AD}$ was also considered to influence the tactile spatial discriminability. Our recent study has, for the first time, indicated that patients with $\mathrm{MCI}$ and $\mathrm{AD}$ have substantial performance deficiencies in tactile angle discrimination compared to normal individuals [37••]. Although these findings are considered to improve the sensitivity and accuracy of AD diagnosis and treatment, the evidence also needs a tenable underlying neural circuit theory from neuroimaging or EEG studies.

\section{EEG and fMRI Findings in MCI and AD}

One of the most recently developed forms of neuroimaging to measure the hemodynamic responses related to neural activities is fMRI. Since the early 1990s, fMRI has been dominate in brain mapping research because it is a noninvasive technology and can obtain both anatomic and functional images with millimeter-range spatial resolution. Moreover, the EEG is now widely used to measure the electrical activity of the brain with millisecond-range temporal resolution. Including our studies $[36,38]$, many researchers have used these technologies to investigate the cognitive task-related brain activities of different modalities. Recently, some studies also investigated the brain activities of $\mathrm{MCI}$ and $\mathrm{AD}$ patients using fMRI and EEG, and tried to find the brain dysfunctions that were considered of use as the clinical indicators.

\section{Memory-Based Indicators}

The term "memory" represents a simplified summation of mental abilities that depend on several systems within the brain. Neuropsychological, neuroanatomical, and neuroimaging research have provided that the memory system is composed of multiple and separate systems supported by different neuroanatomical structures. Current thinking indicates six major memory systems that have been characterized as episodic memory, semantic memory, simple classical conditioning, procedural memory, working memory, and priming [39]. Recently, studies with AD and MCI patients have shown some of these memory systems to be disrupted, and others to be preserved. Specifically, memory deficits in $\mathrm{AD}$ and MCI patients mainly occurred in episodic memory, semantic memory, procedural memory, and working memory systems (see Table 1) [39, 40]. In this section, we will summarize the current understanding of memory deficits that $\mathrm{AD}$ and MCI patients experience from the point of view of functional neuroimaging and EEG.

Previous studies have indicated that episodic memory tasks activated a wide number of brain regions, including the hippocampus [41], anterior thalamic nucleus [42], and prefrontal cortex [43] among others. Numerous early lesion studies and more recent research in neuroimaging have also shown that the core of the episodic memory system is supported by the medial temporal lobes, including the hippocampus and the adjacent entorhinal, perirhinal, and parahippocampal cortices [44]. The deficiency of episodic memory is generally among one of the earliest signs and symptoms of AD patients [45-47]. These memory impairments were considered to be caused by memory related brain cortex atrophy. Recently, structural MRI studies have demonstrated that hippocampus and entorhinal cortex atrophy are seen in MCI and consistently predict progression to dementia of the AD type [48-53]. Moreover, numerous fMRI studies with $\mathrm{AD}$ and MCI patients performing episodic memory tasks also consistently demonstrated decreased activation in the hippocampus and related structures in this region compared with normal aging individuals [54-59, $60 \bullet$. However, except hippocampus, in other brain regions related to episodic memory, such as in prefrontal regions, there are some inconsistent conclusions of brain activation between $\mathrm{AD}$ patients and control patients during the episodic memory task $[56,61 \bullet \bullet, 62,63]$. In particular, some studies $[56,63]$ demonstrated the increased brain activation of prefrontal regions during encoding of the episodic memory task in patients with $\mathrm{AD}$ compared with control patients, whereas others have described the decreased activation in the region during the recognition and retrieval of episodic information $[61 \bullet \cdot$. Therefore, the clinical prediction measure that combines cognitive features of episodic memory impairments and the neuroimaging evidences of the lower 
Table 1 The concepts and related major brain structures of the four memory systems

\begin{tabular}{|c|c|c|c|}
\hline Memory system & Simple concept & Major brain structures & $\begin{array}{l}\text { Disorder with } \\
\text { deficits }\end{array}$ \\
\hline Episodic & $\begin{array}{l}\text { Consciously remembering a particular episode } \\
\text { of one's life }\end{array}$ & $\begin{array}{l}\text { Medial temporal lobes, anterior thalamic nucleus, } \\
\text { mammillary body, fornix, prefrontal cortex }\end{array}$ & $\mathrm{AD}, \mathrm{MCI}$ \\
\hline Semantic & Store of conceptual and factual knowledge & Inferolateral temporal lobes, prefrontal cortex & $\mathrm{AD}, \mathrm{MCI}$ \\
\hline Procedural & Ability to learn cognitive and behavioral skills & $\begin{array}{l}\text { Basal ganglia, cerebellum, supplementary motor } \\
\text { areas }\end{array}$ & \\
\hline Working & $\begin{array}{l}\text { Ability to temporarily maintain and manipulate } \\
\text { information }\end{array}$ & $\begin{array}{l}\text { Phonologic: prefrontal cortex, Broca's area, } \\
\text { Wernicke's area } \\
\text { Spatial: prefrontal cortex, visual-association areas }\end{array}$ & $\mathrm{AD}, \mathrm{MCI}$ \\
\hline
\end{tabular}

$A D$ Alzheimer's disease; $M C I$ mild cognitive impairment

activity and atrophy in the hippocampus tissue were considered to be of use as an accurate clinical indicator for early diagnosis of $\mathrm{AD}$.

Semantic memory refers to our general store of conceptual and factual knowledge unrelated to any specific experiences. The most recent study from Binder and Desai [64] presented a more comprehensive summary that modalityspecific activation of brain regions was found during language comprehension tasks. For instance, the activation peaks of action concepts were found in action-related areas including primary and secondary sensorimotor regions $[65$, 66]. Similarly, activation peaks of emotional concepts were in the superior temporal and ventromedial prefrontal cortex, the areas that play a central role in emotion [67, 68]. The biggest benefits of semantic processing tasks may be in the assessment of risk for $\mathrm{AD}$ and the prognosis for future cognitive decline [69•]; unlike episodic memory skills, semantic memory abilities are commonly affected during $\mathrm{AD}$ [70-72], but remain relatively intact with normal aging [73].

Working memory and procedural memory systems are also very important for humans. However, procedural memory is nondeclarative; the deficit will only be detected for $\mathrm{AD}$ patients with severe episodic memory impairments [40]. In contrast, previous studies suggest that MCI and early stage $\mathrm{AD}$ patients show convincing deficits related to working memory $[74,75]$. These deficits may be understandable from the evidence from previous fMRI $[76,77]$ and EEG [78] studies, in which the working memory was believed to be largely mediated by frontal-subcortical structures. The atrophy or damage to the frontal lobes in $\mathrm{AD}$ patients may lead to the deficits of working memory.

As discussed above, memory dysfunctions are a very convincing sign for $\mathrm{AD}$ in patients. In fact, both the evidence from fMRI and EEG studies also demonstrate that the functional and anatomical changes in brain cortices are detectable in the early stages of AD. Specifically, the hippocampal atrophy and hippocampus-related memory impairments are typical markers of AD. Therefore, memory dysfunction is a sensitive marker for the diagnosis of $\mathrm{AD}$ and for predicting the progression to $\mathrm{AD}$.

\section{Deficits in Non-Memory-Based Cognitive Domains}

The cognitive domains of humans involve knowledge and the development of intellectual skills. Except the memorybased cognitive domains as described above, the non-memory-based cognitive domains, including mental speed, executive tests, category fluency, and auditory attention span, also play a very important role in human daily life. It is well known that the memory problems as described above are some of the signs of AD. On the other hand, AD patients also show deficiencies in non-memory-based cognitive domains, including mental speed, visuospatial perception, motion perception, and attention among others. For instance, a number of behavioral studies demonstrated that patients with $\mathrm{AD}$ had visuospatial and attentional deficiencies such as impaired depth perception [79, 80], motion perception [81, 82], and disengaging and shifting attention [83]. To investigate the underlying neural basis related to these deficiencies, recent studies have also used fMRI and EEG to find the characteristics of non-memory based cognitive functions of $\mathrm{AD}$ and $\mathrm{MCI}$ patients.

Previous fMRI studies $[84 \bullet, 85]$ used visuospatial tasks to explore the differences of brain activation between normal individuals and $\mathrm{AD}$ patients. They indicated that the normal patients activated brain areas including the superior parietal lobule, parieto-occipital junction, and premotor areas during the visuospatial task; however, the AD patients showed reduced activation in these areas. In contrast, the $\mathrm{AD}$ patients showed greater activation in the inferior parietal lobule and recruitment of additional regions. Moreover, recent EEG studies have used visual [86] and auditory [87•] oddball tests to elicit event-related potentials (ERPs) with $\mathrm{AD}$ and MCI patients. Both of these studies revealed that the latencies of ERPs in $\mathrm{AD}$ and MCI patients were 
significantly more prolonged than that of normal individuals. This evidence suggested that the disconnection among the brain areas of AD patients may contribute to brain dysfunction such as impaired or abnormally greater activations. Despite these insights, little work so far has examined the functional brain activations of non-memory-based cognitive domains in patients with $\mathrm{AD}$. To explore the possibility of a neuroimaging marker assisting in the diagnosis of $\mathrm{AD}$, more longitudinal follow-up studies are needed.

Compared to the task-related fMRI studies [84•, 85, 88], a large number of resting state or default mode network (DMN) in fMRI studies [89] with AD and MCI patients have been performed. One of the reasons may be that these task-related fMRI tasks require the active participation of subjects, which may be difficult for some $\mathrm{AD}$ and $\mathrm{MCI}$ patients. This problem can be resolved by the development of resting state fMRI because no stimulation or task-related responses are required. The DMN has been hypothesized based on the observation that specific regions of the brain are consistently activated during the resting state [90]. The DMN typically includes the precuneus/posterior cingulate, the medial frontal and lateral parietal cortices, and hippocampal regions, which are areas of known pathologic change in $\mathrm{AD}$ and $\mathrm{MCI}$ patients. For example, recent studies [91, 92] have demonstrated changed connectivity between the hippocampus and several neocortical regions including the posterior cingulate cortex, lateral temporal cortex, and medial and inferior parietal cortex. Therefore, examining DMN activity may also allow future studies to provide brain function markers for use in the diagnosis of AD.

\section{Conclusions and Future Directions}

In summary, previous studies have demonstrated that the abnormal sensory information processing and brain dysfunction of $\mathrm{AD}$ patients can be detected using neuropsychological tests, fMRI, and EEG approaches. Both of the neuropsychological tests, such as MMSE and CDR, and other cognitive tasks discussed in this review demonstrate specific alterations of several cognitive functions. Alternated activations of several brain areas of $\mathrm{AD}$ patients from task-related fMRI and DMN have been observed. Furthermore, the EEG studies have indicated that the ERPs have significantly longer latencies in AD patients than in normal individuals. Taken together, the studies reviewed above indicate that a number of techniques are useful as early diagnostic aids for $\mathrm{AD}$ and MCI patients. However, these techniques have their own limitations that are considered to influence the sensitivity and accuracy of the early detection of AD. For example, the subjective, personal decision of the physician may decrease the accuracy of neuropsychological tests. Even though fMRI can measure brain activity with a particularly high spatial resolution, the temporal resolution is far from ideal. In contrast, EEG has a lack of spatial resolution. Therefore, researchers need to perform more combined studies with AD patients, such as the simultaneous use of EEG and fMRI, to solve the problem of unbalance between spatial and temporal resolutions. Furthermore, future research should also consider combining neuropsychological and neuroimaging markers with preclinical indicators from other domains, such as molecular neurobiology, to improve the sensitivity of $\mathrm{AD}$ diagnosis and treatment.

Acknowledgment A portion of this study was supported by a Grantin-Aid for Scientific Research (B) 21404002, Japan and the AA Science Platform Program of the Japan Society for the Promotion of Science.

Disclosures No potential conflicts of interest relevant to this article were reported.

\section{References}

Papers of particular interest, published recently, have been highlighted as follows:

- Of importance

•- Of major importance

1. Gauthier S, Reisberg B, Zaudig M, Petersen RC, Ritchie K, Broich K, et al. Mild cognitive impairment. Lancet. 2006;367(9518):126270

2. Petersen RC, Smith GE, Waring SC, Ivnik RJ, Tangalos EG, Kokmen E. Mild cognitive impairment: clinical characterization and outcome. Arch Neurol. 1999;56(3):303-8.

3. Ritchie K, Touchon J. Mild cognitive impairment: conceptual basis and current nosological status. Lancet. 2000;355(9199):225-8.

4. Petersen RC, Doody R, Kurz A, Mohs RC, Morris JC, Rabins PV, et al. Current concepts in mild cognitive impairment. Arch Neurol. 2001;58(12):1985-92.

5. Shah Y, Tangalos EG, Petersen RC. Mild cognitive impairment. When is it a precursor to Alzheimer's disease? Geriatrics. 2000;55 (9):62. 5-8.

6. Consensus report of the Working Group on: "Molecular and Biochemical Markers of Alzheimer's Disease. The Ronald and Nancy Reagan Research Institute of the Alzheimer's Association and the National Institute on Aging Working Group. Neurobiol Aging. 1998;19(2):109-16.

7. Fagan AM, Mintun MA, Mach RH, Lee SY, Dence CS, Shah AR, et al. Inverse relation between in vivo amyloid imaging load and cerebrospinal fluid A beta(42) in humans. Ann Neurol. 2006;59 (3):512-9.

8. Blennow K, Hampel H. CSF markers for incipient Alzheimer's disease. Lancet Neurol. 2003;2(10):605-13.

9. Buerger K, Ewers M, Pirttila T, Zinkowski R, Alafuzoff I, Teipel SJ, et al. CSF phosphorylated tau protein correlates with neocortical neurofibrillary pathology in Alzheimer's disease. Brain. 2006;129(Pt 11):3035-41.

10. Hansson O, Zetterberg H, Buchlave P, Londos E, Blennow K, Minthon L. Association between CSF biomarkers and incipient Alzheimer's disease in patients with mild cognitive impairment: a follow-up study. (vol 5, pg 228, 2006). Lancet Neurol. 2006;5 (4):293-3. 
11. Hansson O, Buchhave P, Zetterberg H, Blennow K, Minthon L, Warkentin S. Combined rCBF and CSF biomarkers predict progression from mild cognitive impairment to Alzheimer's disease. Neurobiol Aging. 2009;30(2):165-73.

12. Bouwman FH, Schoonenboom SN, van der Flier WM, van Elk EJ, Kok A, Barkhof F, et al. CSF biomarkers and medial temporal lobe atrophy predict dementia in mild cognitive impairment. Neurobiol Aging. 2007;28(7):1070-4.

13. Zhong Z, Ewers M, Teipel S, Burger K, Wallin A, Blennow K, et al. Levels of beta-secretase (BACE1) in cerebrospinal fluid as a predictor of risk in mild cognitive impairment. Arch Gen Psychiatry. 2007;64(6):718-26.

14. Hampel H, Frank R, Broich K, Teipel SJ, Katz RG, Hardy J, et al. Biomarkers for Alzheimer's disease: academic, industry and regulatory perspectives. Nat Rev Drug Discov. 2010;9 (7):560-74.

15. Hampel H, Shen Y, Walsh DM, Aisen P, Shaw LM, Zetterberg H, et al. Biological markers of amyloid beta-related mechanisms in Alzheimer's disease. Exp Neurol. 2010;223(2):334-46.

16. Ewers M, Zhong Z, Burger K, Wallin A, Blennow K, Teipel SJ, et al. Increased CSF-BACE 1 activity is associated with ApoEepsilon 4 genotype in subjects with mild cognitive impairment and Alzheimer's disease. Brain. 2008;131(Pt 5):1252-8.

17. He P, Zhong Z, Lindholm K, Berning L, Lee W, Lemere C, et al. Deletion of tumor necrosis factor death receptor inhibits amyloid beta generation and prevents learning and memory deficits in Alzheimer's mice. J Cell Biol. 2007;178(5):82941.

18. Ishii $\mathrm{K}$ et al. Age, $\mathrm{APOE} \varepsilon 4$, and Ethnic Effect on $[\mathrm{C}-11] \mathrm{PiB}$ in Multi-national ADNI Studies - Direct Comparison of J-ADNI, USADNI and AIBL Data. Alzheimer's Association International Conference on Alzheimer's Disease 2011, Paris, France.

19. Frisoni $\mathrm{G}$ et al. Estimating the Impact of Differences among Protocols for Manual Hippocampal Segmentation on Alzheimer's Disease-Related Atrophy: Preparatory Phase for a Harmonized Protocol. Alzheimer's Association International Conference on Alzheimer's Disease 2011, Paris, France.

20. Tobimatsu S, Celesia GG. Studies of human visual pathophysiology with visual evoked potentials. Clin Neurophysiol. 2006;117 (7):1414-33.

21. Cook IA, Leuchter AF. Synaptic dysfunction in Alzheimer's disease: clinical assessment using quantitative EEG. Behav Brain Res. 1996;78(1):15-23.

22. Kendell RE. Diagnostic and statistical manual of mental-disorders, 3rd Edition - Amer-Psychiatric-Assoc. Am J Psychiat. 1980;137 (12):1630-1.

23. McKhann G, Drachman D, Folstein M, Katzman R, Price D, Stadlan EM. Clinical diagnosis of Alzheimer's disease: report of the NINCDS-ADRDA Work Group under the auspices of Department of Health and Human Services Task Force on Alzheimer's Disease. Neurology. 1984;34(7):939-44.

24. Hughes CP, Berg L, Danziger WL, Coben LA, Martin RL. A new clinical scale for the staging of dementia. Br J Psychiatry. 1982;140:566-72.

25. Reisberg B, Ferris SH, de Leon MJ, Crook T. The global deterioration scale for assessment of primary degenerative dementia. Am J Psychiatry. 1982;139(9):1136-9.

26. Folstein MF, Folstein SE, McHugh PR. Mini-mental state. A practical method for grading the cognitive state of patients for the clinician. J Psychiatr Res. 1975;12(3):189-98.

27. Mungas D. In-office mental status testing: a practical guide. Geriatrics. 1991;46(7):54-8. 63, 6.

28. Anthony JC, LeResche L, Niaz U, von Korff MR, Folstein MF. Limits of the 'Mini-Mental State' as a screening test for dementia and delirium among hospital patients. Psychol Med. 1982;12 (2):397-408.
29. Galasko D, Klauber MR, Hofstetter CR, Salmon DP, Lasker B, Thal LJ. The mini-mental state examination in the early diagnosis of Alzheimers-Disease. Arch Neurol. 1990;47(1):49-52.

30. Della Sala S, Kinnear P, Spinnler H, Stangalino C. Color-to-figure matching in Alzheimer's disease. Arch Clin Neuropsychol. 2000;15(7):571-85.

31. Backman L, Small BJ. Cognitive deficits in preclinical Alzheimer's disease and vascular dementia: patterns of findings from the Kungsholmen Project. Physiol Behav. 2007;92(1-2):80-6.

32. Backman L, Small BJ, Fratiglioni L. Stability of the preclinical episodic memory deficit in Alzheimer's disease. Brain. 2001;124 (Pt 1):96-102.

33. Parra MA, Abrahams S, Fabi K, Logie R, Luzzi S, Della Sala S. Short-term memory binding deficits in Alzheimer's disease. Brain. 2009;132(Pt 4):1057-66.

34. Hodges JR, Greene JDW. Knowing about people and naming them: can Alzheimer's disease patients do one without the other? Q J Exp Psychol A. 1998;51(1):121-34.

35. Tippett LJ, Blackwood K, Farah MJ. Visual object and face processing in mild-to-moderate Alzheimer's disease: from segmentation to imagination. Neuropsychologia. 2003;41(4):453-68.

36. Yang J, Han H, Chui D, Shen Y, Wu J. Prominent activation of the intraparietal and somatosensory areas during angle discrimination by intra-active touch. Hum Brain Mapp. 2011. doi:10.1002/ hbm. 21419 .

37. •• Yang J, Ogasa T, Ohta Y, Abe K, Wu J. Decline of human tactile angle discrimination in patients with mild cognitive impairment and Alzheimer's disease. J Alzheimers Dis. 2010;22(1):225-34. This is the first study to report that patients with MCI and AD have substantial performance deficits in tactile angle discrimination compared to the normal individuals.

38. Wu J, Li Q, Bai O, Touge T. Multisensory interactions elicited by audiovisual stimuli presented peripherally in a visual attention task: a behavioral and event-related potential study in humans. J Clin Neurophysiol. 2009;26(6):407-13.

39. Squire LR. Memory systems of the brain: a brief history and current perspective. Neurobiol Learn Mem. 2004;82(3):171-7.

40. Budson AE, Price BH. Memory dysfunction. N Engl J Med. 2005;352(7):692-9.

41. Hamani C, McAndrews MP, Cohn M, Oh M, Zumsteg D, Shapiro $\mathrm{CM}$, et al. Memory enhancement induced by hypothalamic/fornix deep brain stimulation. Ann Neurol. 2008;63(1):119-23.

42. Stenset V, Grambaite R, Reinvang I, Hessen E, Cappelen T, Bjornerud A, et al. Diaschisis after thalamic stroke: a comparison of metabolic and structural changes in a patient with amnesic syndrome. Acta Neurol Scand Suppl. 2007;187:68-71.

43. Desgranges B, Baron JC, Eustache F. The functional neuroanatomy of episodic memory: the role of the frontal lobes, the hippocampal formation, and other areas. NeuroImage. 1998;8(2):198213.

44. Squire LR, Zola-Morgan S. The medial temporal lobe memory system. Science. 1991;253(5026):1380-6.

45. Dickerson BC, Sperling RA. Functional abnormalities of the medial temporal lobe memory system in mild cognitive impairment and Alzheimer's disease: insights from functional MRI studies. Neuropsychologia. 2008;46(6):1624-35.

46. Dickerson BC, Sperling RA. Large-scale functional brain network abnormalities in Alzheimer's disease: insights from functional neuroimaging. Behav Neurol. 2009;21(1):63-75.

47. Sperling RA, Dickerson BC, Pihlajamaki M, Vannini P, LaViolette $\mathrm{PS}$, Vitolo OV, et al. Functional alterations in memory networks in early Alzheimer's disease. Neuromolecular Med. 2010;12(1):2743.

48. Mosconi L, Brys M, Glodzik-Sobanska L, De Santi S, Rusinek H, de Leon MJ. Early detection of Alzheimer's disease using neuroimaging. Exp Gerontol. 2007;42(1-2):129-38. 
49. de Leon MJ, Mosconi L, Blennow K, DeSanti S, Zinkowski R, Mehta PD, et al. Imaging and CSF studies in the preclinical diagnosis of Alzheimer's disease. Ann Ny Acad Sci. 2007;1097:114-45.

50. Du AT, Schuff N, Amend D, Laakso MP, Hsu YY, Jagust WJ, et al. Magnetic resonance imaging of the entorhinal cortex and hippocampus in mild cognitive impairment and Alzheimer's disease. J Neurol Neurosurg Psychiatry. 2001;71(4):441-7.

51. Jack Jr CR, Dickson DW, Parisi JE, Xu YC, Cha RH, O'Brien PC, et al. Antemortem MRI findings correlate with hippocampal neuropathology in typical aging and dementia. Neurology. 2002;58 (5):750-7.

52. Killiany RJ, Gomez-Isla T, Moss M, Kikinis R, Sandor T, Jolesz F, et al. Use of structural magnetic resonance imaging to predict who will get Alzheimer's disease. Ann Neurol. 2000;47(4):430-9.

53. Scheltens P, Fox N, Barkhof F, De Carli C. Structural magnetic resonance imaging in the practical assessment of dementia: beyond exclusion. Lancet Neurol. 2002;1(1):13-21.

54. Small SA, Perera GM, DeLaPaz R, Mayeux R, Stern Y. Differential regional dysfunction of the hippocampal formation among elderly with memory decline and Alzheimer's disease. Ann Neurol. 1999;45(4):466-72.

55. Golby A, Silverberg G, Race E, Gabrieli S, O'Shea J, Knierim K, et al. Memory encoding in Alzheimer's disease: an fMRI study of explicit and implicit memory. Brain. 2005;128:773-87.

56. Remy F, Mirrashed F, Campbell B, Richter W. Verbal episodic memory impairment in Alzheimer's disease: a combined structural and functional MRI study. NeuroImage. 2005;25(1):253-66.

57. Rombouts SA, Barkhof F, Veltman DJ, Machielsen WC, Witter MP, Bierlaagh MA, et al. Functional MR imaging in Alzheimer's disease during memory encoding. AJNR Am J Neuroradiol. 2000;21(10):1869-75.

58. Miller SL, Celone K, DePeau K, Diamond E, Dickerson BC, Rentz $\mathrm{D}$, et al. Age-related memory impairment associated with loss of parietal deactivation but preserved hippocampal activation. Proc Natl Acad Sci U S A. 2008;105(6):2181-6.

59. Pariente J, Cole S, Henson R, Clare L, Kennedy A, Rossor M, et al. Alzheimer's patients engage an alternative network during a memory task. Ann Neurol. 2005;58(6):870-9.

60. - Erk S, Spottke A, Meisen A, Wagner M, Walter H, Jessen F. Evidence of neuronal compensation during episodic memory in subjective memory impairment. Arch Gen Psychiatry. 2011;68 (8):845-52. This study demonstrated that subjective memory impairment is accompanied by functional alterations in hippocampal integrity that reflect early neuronal dysfunction and by compensatory mechanisms that preserve memory performance.

61. • Schwindt GC, Black SE. Functional imaging studies of episodic memory in Alzheimer's disease: a quantitative meta-analysis. NeuroImage. 2009;45(1):181-90. This is the first meta-analysis of episodic memory tasks related to functional neuroimaging in $A D$. This study demonstrated that this is not a simple black-andwhite distinction, as they found that the prefrontal cortices did not showed consistent activation of AD compared to normal during the memory tasks.

62. Gron G, Bittner D, Schmitz B, Wunderlich AP, Riepe MW. Subjective memory complaints: objective neural markers in patients with Alzheimer's disease and major depressive disorder. Ann Neurol. 2002;51(4):491-8.

63. Wierenga CE, Stricker NH, McCauley A, Simmons A, Jak AJ, Chang YL, et al. Altered brain response for semantic knowledge in Alzheimer's disease. Neuropsychologia. 2011;49(3):392-404.

64. Binder JR, Desai RH. The neurobiology of semantic memory. Trends Cogn Sci. 2011;15(11):527-36.

65. Hoenig K, Sim EJ, Bochev V, Herrnberger B, Kiefer M. Conceptual flexibility in the human brain: dynamic recruitment of semantic maps from visual, motor, and motion-related areas. J Cognitive Neurosci. 2008;20(10):1799-814.
66. Pulvermuller F, Shtyrov Y, Ilmoniemi R. Brain signatures of meaning access in action word recognition. J Cognitive Neurosci. 2005;17(6):884-92.

67. Olson IR, Plotzker A, Ezzyat Y. The Enigmatic temporal pole: a review of findings on social and emotional processing. Brain. 2007;130(Pt 7):1718-31.

68. Etkin A, Egner T, Kalisch R. Emotional processing in anterior cingulate and medial prefrontal cortex. Trends Cogn Sci. 2011;15 (2):85-93.

69. - Sugarman MA, Woodard JL, Nielson KA, Seidenberg M, Smith JC, Durgerian S et al. Functional magnetic resonance imaging of semantic memory as a presymptomatic biomarker of Alzheimer's disease risk. Biochim Biophys Acta. 2011. in press. This review indicated that the semantic memory processing tasks, in conjunction with other risk factors or biomarkers, may provide a sensitive and comprehensive estimate of an individual's risk for dementia.

70. Hodges JR, Salmon DP, Butters N. Semantic memory impairment in Alzheimer's disease: failure of access or degraded knowledge? Neuropsychologia. 1992;30(4):301-14.

71. Hodges JR, Salmon DP, Butters N. Differential impairment of semantic and episodic memory in Alzheimer's and Huntington's diseases: a controlled prospective study. J Neurol Neurosurg Psychiatry. 1990;53(12):1089-95.

72. Nebes RD. Semantic memory in Alzheimer's disease. Psychol Bull. 1989;106(3):377-94.

73. Nilsson LG. Memory function in normal aging. Acta Neurol Scand Suppl. 2003;179:7-13.

74. Belleville S, Chertkow H, Gauthier S. Working memory and control of attention in persons with Alzheimer's disease and mild cognitive impairment. Neuropsychology. 2007;21(4):458-69.

75. Lancaster TM, Baird A, Wolf C, Jackson MC, Johnston SJ, Donev R, et al. Neural hyperactivation in carriers of the Alzheimer's risk variant on the clusterin gene. Eur Neuropsychopharmacol. 2011;21 (12):880-4.

76. West RL. An application of prefrontal cortex function theory to cognitive aging. Psychol Bull. 1996;120(2):272-92.

77. Nystrom LE, Braver TS, Sabb FW, Delgado MR, Noll DC, Cohen JD. Working memory for letters, shapes, and locations: fMRI evidence against stimulus-based regional organization in human prefrontal cortex. NeuroImage. 2000;11(5 Pt 1):424-46.

78. Sauseng P, Klimesch W, Schabus M, Doppelmayr M. Frontoparietal EEG coherence in theta and upper alpha reflect central executive functions of working memory. Int $\mathrm{J}$ Psychophysiol. 2005;57(2):97-103.

79. Cronin-Golomb A. Vision in Alzheimer's disease. Gerontologist. 1995;35(3):370-6.

80. Mendez MF, Cherrier MM, Meadows RS. Depth perception in Alzheimer's disease. Percept Mot Skills. 1996;83(3 Pt 1):987-95.

81. Rizzo M, Anderson SW, Dawson J, Myers R, Ball K. Visual attention impairments in Alzheimer's disease. Neurology. 2000;54(10):1954-9.

82. Rizzo M, Anderson SW, Dawson J, Nawrot M. Vision and cognition in Alzheimer's disease. Neuropsychologia. 2000;38(8):1157-69.

83. Filoteo JV, Delis DC, Massman PJ, Demadura T, Butters N, Salmon DP. Directed and divided attention in Alzheimer's disease: impairment in shifting of attention to global and local stimuli. J Clin Exp Neuropsychol. 1992;14(6):871-83.

84. - Thiyagesh SN, Farrow TF, Parks RW, Accosta-Mesa H, Young $\mathrm{C}$, Wilkinson ID, et al. The neural basis of visuospatial perception in Alzheimer's disease and healthy elderly comparison subjects: an fMRI study. Psychiatry Res. 2009;172(2):109-16. This is the first study to explore the different of neural mechanisms underlying of depth and motion perception between AD patients and normal individuals.

85. Prvulovic D, Hubl D, Sack AT, Melillo L, Maurer K, Frolich L, et al. Functional imaging of visuospatial processing in Alzheimer's disease. NeuroImage. 2002;17(3):1403-14. 
86. Kubova Z, Kremlacek J, Valis M, Langrova J, Szanyi J, Vit F, et al. Visual evoked potentials to pattern, motion and cognitive stimuli in Alzheimer's disease. Doc Ophthalmol. 2010;121(1):37-49.

87. - Lai CL, Lin RT, Liou LM, Liu CK. The role of event-related potentials in cognitive decline in Alzheimer's disease. Clin Neurophysiol. 2010;121(2):194-9. This study indicated that the event-related potentials may reflect cognitive decline more sensitively than neuropsychological tests in the longitudinal follow-up of AD patients.

88. Hao J, Li K, Zhang D, Wang W, Yang Y, Yan B, et al. Visual attention deficits in Alzheimer's disease: an fMRI study. Neurosci Lett. 2005;385(1):18-23.
89. Beason-Held LL. Dementia and the default mode. Curr Alzheimer Res. 2011;8(4):361-5.

90. Raichle ME, MacLeod AM, Snyder AZ, Powers WJ, Gusnard DA, Shulman GL. A default mode of brain function. Proc Natl Acad Sci U S A. 2001;98(2):676-82.

91. Allen G, Barnard H, McColl R, Hester AL, Fields JA, Weiner MF, et al. Reduced hippocampal functional connectivity in Alzheimer disease. Arch Neurol. 2007;64(10):1482-7.

92. Zhang HY, Wang SJ, Xing J, Liu B, Ma ZL, Yang M, et al. Detection of PCC functional connectivity characteristics in resting-state fMRI in mild Alzheimer's disease. Behav Brain Res. 2009;197(1):103-8. 